\title{
INDUCED MUTATIONS AT THE V'by LOCUS OF TRIFOLIUM REPENS
}

\section{EFFECTS OF ACUTE, CHRONIC AND FRACTIONATED DOSES OF GAMMA RADIATION ON INDUCTION OF SOMATIC MUTATIONS}

\author{
D. ROY DAVIES and E. T. WALL \\ Isotope Research Division (A.E.R.E.), Wantage Radiation Laboratory, Berkshire
}

\section{INTRODUCTION}

Received I6.xi.59

Considerable attention has been devoted recently to the possibility of increasing the frequency of occurrence of somatic mutations in plants by exposing them to ionising radiations, and to this end a tremendous number of samples of different species and varieties have been treated. Very little basic information, however, is available regarding the induction of these mutations, and in this paper results are presented of the comparative effects of acute, fractionated and chronic doses of gamma radiation on somatic mutation rates. Such comparative studies have previously been made in plants only in terms of induced chromosome breakage (e.g. Lane, I952; Steffenson and Arnason, I954; Sax $e t$ al., I955) and of growth, survival and mutation induction after exposure of seeds (Kaplan, I95 I ; Schooler et al., I957). Cuany et al. (r958) have exposed clonal lines of Antirrhinum majus heterozygous for three colour genes, to one dose of acute X-irradiation and to chronic gamma irradiation at various dose rates, but no data are available which allow a comparison of the effects of the two treatments.

The studies reported here were concerned with the somatic mutations induced by gamma radiation at the leaf marking locus of diploid white clover (Trifolium repens). The allele studied was Vby, one of eleven at this locus (Brewbaker and Carnahan, I956), which results in the production of a phenotype distinguished by the presence of a broken white $\mathrm{V}$ surmounted by a yellow tip (plate I, fig. I). No crossing-over has been reported between the constituent parts of the locus. Two clones derived from two sister plants and heterozygous for this allele and the recessive allele $v$, which in the homozygous condition results in the complete absence of a leaf mark, were produced for the series of experiments. Most allelic compounds at this locus, apart from those involving $v$, exhibit mosaic dominance, though one allele- $\mathrm{V}^{\mathrm{B}}$-is partially or completely dominant to four other alleles (Brewbaker, I955).

Though the primary aim of the study was an elucidation of the effect of dose fractionation, it was also of interest to note the range of mutant phenotypes produced in this somatic tissue. Since the gene being investigated is already known to exist in allelic forms of varying 
expression, there seemed a good opportunity of producing and detecting new phenotypic expressions, and as the locus probably has little physiological effect, mutants would not be at a disadvantage. The locus is also advantageous for mutation experiments, in that large numbers of leaves can easily be grown and examined for mutations, but it has a disadvantage in that mutation rates can not be determined, as the number of potential units of mutation is unknown. The only value that can be determined is the frequency of occurrence of leaves showing mutations.

The term mutation of the leaf marking allele is used in its broadest sense. True gene or point mutations cannot here be distinguished from partial or whole chromosome losses, and it is quite likely that chromosomal deficiencies represent a large part of the induced mutations. The time of appearance after treatment of the first mutations varied according to the conditions of growth, from four weeks in summer to ten weeks in winter. Initially mutations were recognised as an absence of, or a change in, a small portion of the leaf mark. Later leaflets had larger segments of mutant tissue, then whole leaflets and ultimately whole leaves and tillers were mutant. The standard scoring procedure was to count mutant leaf marks irrespective of their size, as one mutational event, and if two or more associated leaflets or leaves had similar mutant phenotypes then this was scored as one mutation. The total numbers of leaves produced were recorded and all except those exhibiting mutations removed from the plant after each time of scoring. Mutant leaves were left and marked in order that associated mutations arising later from the same mutational event could be recognised.

No spontaneous mutation was found in the control plants utilised in all the experiments considered here, ( $c a$. I o, ooo leaves) and none has been found in plants used for other experiments.

\section{IRRADIATION TECHNIQUE}

All irradiations were undertaken in a cell specially designed for plant irradiation, at the Wantage Radiation Laboratories (Piggot, in press). This cell which is temperature controlled above ambient to $\pm \mathrm{I}^{\circ} \mathrm{C}$., is large enough to allow a working space around the source. The I 20 curie $\mathrm{Co}^{60}$ source is stored in a lead "coffin" (plate II) sited on the floor of the cell, and can be raised vertically by remote control through a guide tube to any height up to $100 \mathrm{~cm}$. above the turntables on which the plants are located. The turntables are situated on six radial arms in a horizontal plane on the top surface of the lead "coffin." Dose rates of 600 to 6000 rads per hour are provided accurately, reproducibly and uniformly - the rate being controlled by the distance of the turntables from the central guide tube; uniformity throughout the volume being irradiated is ensured by rotating the turntables at I r.p.m. 


\section{THE DOSE-RESPONSE CURVE}

Six uniform tillers of the heterozygous material, each $4^{-6}$ in. long and having initially a similar number of leaves, constituted one treatment sample. These were defoliated and then exposed at room temperature, at a dose rate of Iooo rads per hour, to one of the following doses of gamma rays :-

$$
\text { 500, I000, I500, 2000, 2500, } 3100 \text { and } 4000 \text { rads. }
$$

The plants were irradiated in February, and were first examined 28 days later, and again on the 42 nd, 56 th and 7 oth days after irradiation. The total numbers of mutant and normal leaves from all the scoring dates are given in table I. Up to I 500 rads there was very

TABLE I

Dose-response experiment: numbers of normal and mutant leaves in irradiated Trifolium repens

\begin{tabular}{|c|c|c|c|c|}
\hline \multirow{2}{*}{ Dose in rads } & \multirow{2}{*}{ Total no. leaves } & \multicolumn{2}{|c|}{ Leaves with mutations } & \multirow{2}{*}{$\begin{array}{l}\text { No. mutants } \\
\text { repeated }\end{array}$} \\
\hline & & Number * & Percentage & \\
\hline 500 & 4097 & 9 & 0.22 & 0 \\
\hline IOOO & 4176 & 28 & $0 \cdot 67$ & I \\
\hline I 500 & 4234 & 59 & I 39 & IO \\
\hline 2000 & 3657 & 79 & $2 \cdot 16$ & I 5 \\
\hline 2500 & $335^{8}$ & 89 & $2 \cdot 65$ & I3 \\
\hline 3100 & 3213 & $9^{2}$ & $2 \cdot 86$ & 22 \\
\hline 4000 & $189 \mathrm{I}$ & 75 & $3 \cdot 97$ & I 5 \\
\hline
\end{tabular}

* Repeats scored as I mutational event (=occurrence of same mutation on successive leaves of one tiller).

little effect on leaf production, but above this dose total leaf numbers fell markedly (text-fig. I).

A considerable number of mutations of the leaf mark were observed after exposure to $\gamma$ radiation. At the lowest dose used, 500 rads, there were 0.22 per cent. and at the highest, 4000 rads, there were 3.97 per cent. of leaves with mutations (text-fig. 2). A considerable number of the mutations observed were small gaps either in the white $\mathrm{V}$ or yellow tip. As some of these gaps could conceivably be missed due to their small size, it was decided to include in the tables, graphs and statistical analyses only those mutational events which affected a half-leaflet or larger portion of the tissue. Later analyses showed that the treatment responses in terms of half-leaflet mutations and the smaller gaps were the same, and so the latter were included in the last of the three experiments discussed here.

Statistical analyses of the data were undertaken, to elucidate the nature of the dose response. This involved fitting linear and quadratic functions to the percentage mutant leaves and the dose. For a straight line, the formula is $y=b x+c$ where $b$ and $c$ are estimated by minimising the sums of squares of the errors, and $x$ is the dose in rads. As the 


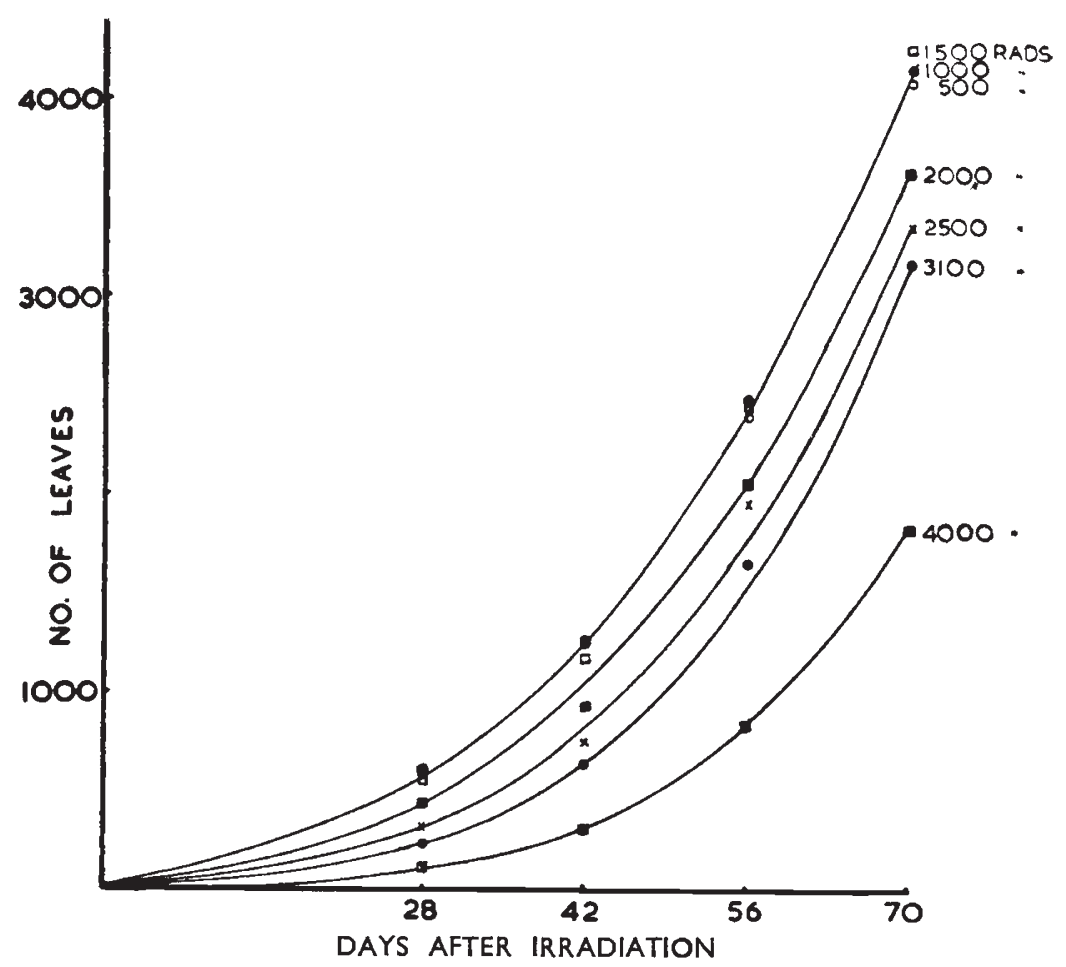

TEXT-FIG. I.-Effect of $\gamma$ radiation on leaf production (T. repens).

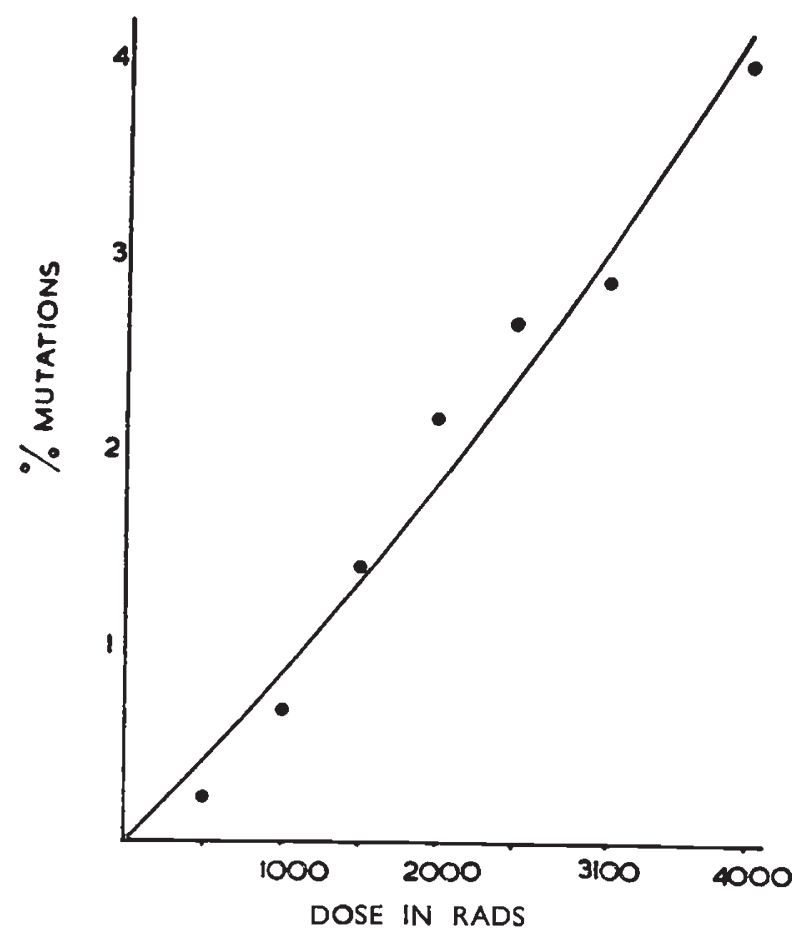

TEXT-FIG. 2.-Effect of $\gamma$ radiation on induction of mutations ( $V$ locus in T. repens). 


\section{Plate I}

Fig. 1.-Leaves of $T$. repens homozygous for the recessive allele " $v$ " (left) and heterozygous for "Vby" and " $v$ " (right).

Fig. 2.- Mutant leaves exhibiting from left to right, the two "yellow tip " and the "broken $\mathrm{V}$ " phenotypes respectively.

Frg. 3.-Mutant leaves with white $V$ reduced to spots and the yellow tip smaller in size.

Frg. 4.-Mutant leaves with various numbers of leaflets exhibiting the "faint mark" phenotype. 


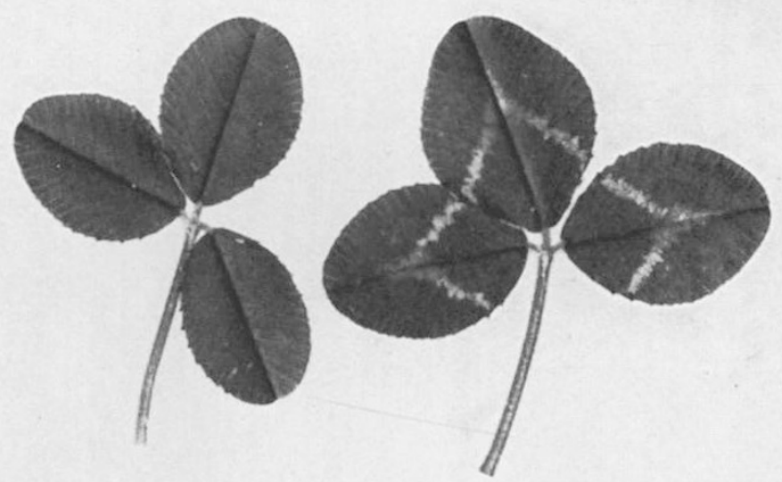

I
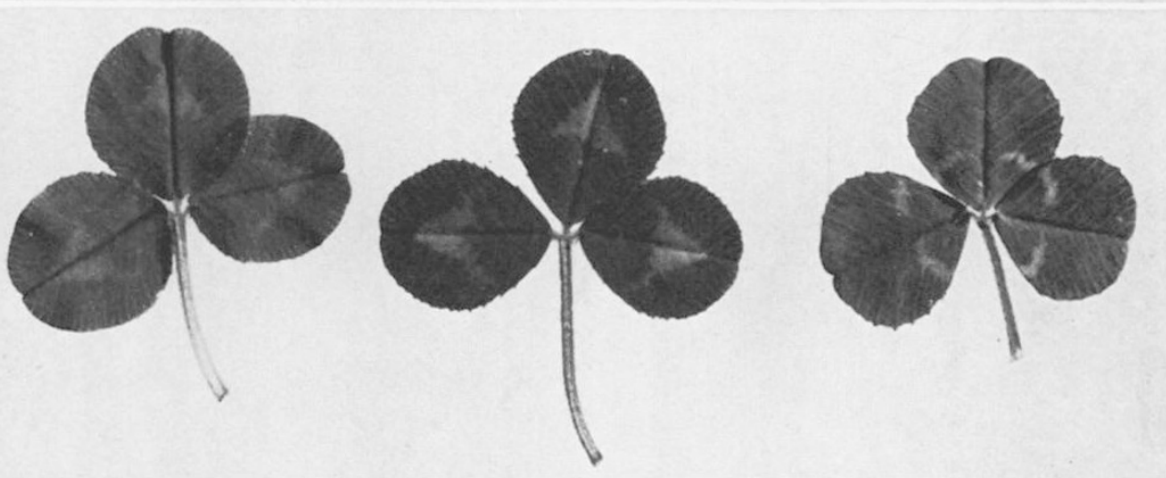

2
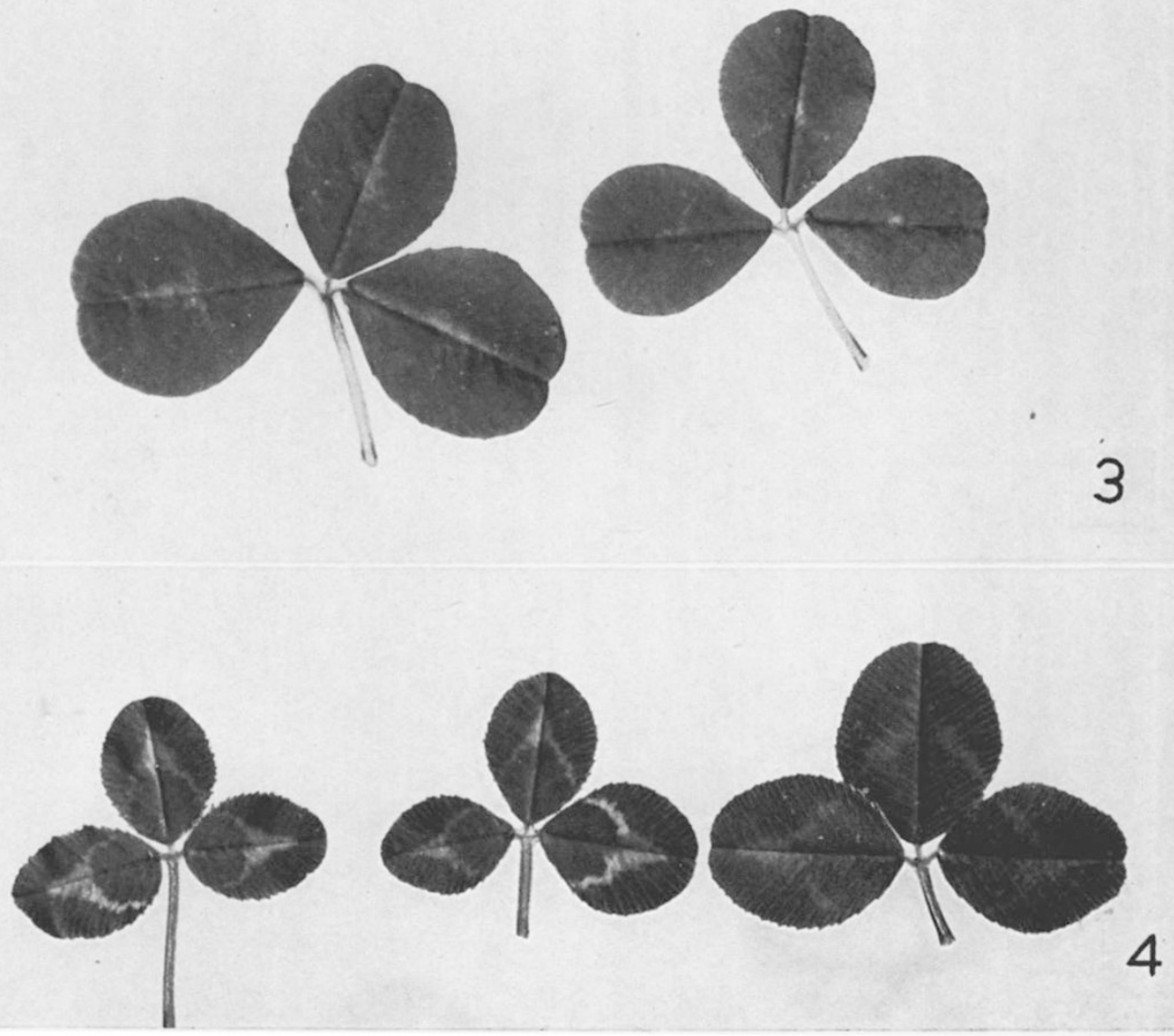
control mutation rate is zero, $c=0$. This gives the relation between the observations and the dose in rads of $y=0.0000097962 x$.

For the quadratic function the formula is $y=a x^{2}+b x+c$, again $a$ and $b$ to be estimated, $x$ the dose in rads, and $c$ being omitted as the control value is zero. This gives a relationship of, $y=0$. 0000092039 $x$ $+0 \cdot 00000000$ IgI $2 x^{2}$.

Substituting for $x$ in these equations, the numbers of mutant leaves expected at each dose were determined, and agreement between observed and expected values tested by calculating $\chi^{2}$.

Testing the goodness of fit with a straight line, $\underset{(6)}{2}=12.002$ and $\mathrm{P}=0 \cdot \mathrm{I} 0$ to $0 \cdot 05$.

TABLE 2

Dose-response experiment. Frequencies of mutant phenotypes

\begin{tabular}{|c|c|c|c|c|c|}
\hline $\begin{array}{c}\text { Dose in } \\
\text { rads }\end{array}$ & $\begin{array}{c}\text { Loss of } \\
\text { complete } \\
\text { mark } \\
\text { (no. and } \\
\text { per cent.) }\end{array}$ & $\begin{array}{l}\text { Loss of } \\
\text { white V } \\
\text { (no. and } \\
\text { per cent.) }\end{array}$ & $\begin{array}{l}\text { Loss of } \\
\text { yellow tip } \\
\text { (no. and } \\
\text { per cent.) }\end{array}$ & $\begin{array}{l}\text { White V } \\
\text { reduced } \\
\text { to spots } \\
\text { (no. and } \\
\text { per cent.) }\end{array}$ & $\begin{array}{l}\text { White V } \\
\text { reduced } \\
\text { in intensity } \\
\text { (no. and } \\
\text { per cent.) }\end{array}$ \\
\hline \multirow[t]{2}{*}{500} & I & 2 & O & $\mathrm{O}$ & 0 \\
\hline & 0.024 & 0.049 & 0 & o & 0 \\
\hline \multirow[t]{2}{*}{1000} & I & 2 & o & o & o \\
\hline & 0.024 & 0.048 & O & o & o \\
\hline \multirow[t]{2}{*}{1500} & 7 & 3 & I & 2 & O \\
\hline & 0.165 & $0.07 \mathrm{I}$ & 0.024 & $0 \cdot 04^{8}$ & 0 \\
\hline \multirow[t]{2}{*}{2000} & 9 & 0 & 2 & 3 & 8 \\
\hline & $0 \cdot 246$ & o & 0.055 & 0.082 & 0.220 \\
\hline \multirow[t]{2}{*}{2500} & $9^{2}$ & 8 & 0 & 3 & 4 \\
\hline & $0 \cdot 268$ & $0.23^{8}$ & o & 0.089 & 0.1 I 9 \\
\hline \multirow[t]{2}{*}{3100} & IO & IO & I & 3 & 8 \\
\hline & 0.3 I I & $0 \cdot 3$ I I & $0.03 \mathrm{I}$ & 0.093 & 0.249 \\
\hline \multirow[t]{2}{*}{4000} & 8 & 7 & 0 & 9 & 8 \\
\hline & 0.423 & $0 \cdot 37^{\circ}$ & 0 & $0 \cdot 476$ & $0 \cdot 423$ \\
\hline
\end{tabular}

Testing the goodness of fit with a quadratic curve, $\chi_{(5)}^{2}=10 \cdot 75^{\mathrm{I}}$ and $\mathrm{P}=0 \cdot \mathrm{I}$ o to $0 \cdot 05$. This shows that the dose-response relationship gives a similar fit to quadratic and linear functions.

A linear relationship has been found for most classes of point mutations studied, over a great range of doses and a great variety of organisms (Muller, I954). Such a relationship indicates that each mutation is a one-hit event. The results of this and the fractionation experiments discussed indicate that at least some of the mutational events recorded here were multi-hit events. At the highest doses studied it is possible that there was a non-recovery of certain mutations due to accompanying lethals-this would result in a flattening of the quadratic curve and suggest a linear relationship, in other words, the quadratic component might well be greater for the induction of mutations than for the visible mutants scored. The different types of mutations observed are shown in plate I, figs. 2-4, and their relative frequencies in table 2, the data being based only on those instances where whole leaflets were mutant and there could be no doubt as to 
their exact nature and extent. Since the rate of occurrence of such whole leaflet mutant types was very low statistical analyses of the dose response in terms of the various mutant phenotypes was not justified.

\section{EFFECT OF DOSE-FRACTIONATION}

In this experiment it was required to compare firstly the effect of splitting a given dose into two or more fractions, and secondly the effect of varying the time intervals between fractions.

Nine similar-sized tillers of each of the two heterozygous clones constituted one treatment sample in this experiment. The tillers were defoliated and then at room temperature, exposed to one of the treatments listed in table 3 , at a dose rate of Iooo rads per hour. The

TABLE 3

Numbers of normal and mutant leaves after acute and fractionated doses.

\begin{tabular}{|c|c|c|c|c|c|c|}
\hline \multirow{2}{*}{$\begin{array}{l}\text { Dose in } \\
\text { rads }\end{array}$} & \multirow{2}{*}{$\begin{array}{l}\text { Time interval } \\
\text { between } \\
\text { fractions (days) }\end{array}$} & \multirow{2}{*}{ Clone } & \multirow{2}{*}{$\begin{array}{l}\text { Total no. } \\
\text { leaves }\end{array}$} & \multicolumn{2}{|c|}{ Leaves with mutations } & \multirow{2}{*}{$\begin{array}{l}\text { No. mutants } \\
\text { repeated }\end{array}$} \\
\hline & & & & Number * & Percentage & \\
\hline 2400 & - & $\underset{I+I I}{I I}$ & $\begin{array}{l}2121 \\
2575 \\
4696\end{array}$ & $\begin{array}{l}30 \\
30 \\
60\end{array}$ & $\begin{array}{l}\mathrm{I} \cdot 4 \mathrm{I} \\
\mathrm{I} \cdot \mathrm{I} 7 \\
\mathrm{I} \cdot 28\end{array}$ & $\begin{array}{l}5 \\
1 \\
6\end{array}$ \\
\hline $2 \times 1200$ & 2 & $\underset{I}{I}$ & $\begin{array}{l}2355 \\
2320 \\
4675\end{array}$ & $\begin{array}{l}28 \\
18 \\
46\end{array}$ & $\begin{array}{l}I \cdot I 9 \\
0.78 \\
0.98\end{array}$ & $\begin{array}{l}2 \\
2 \\
4\end{array}$ \\
\hline $2 \times 1200$ & 4 & $\underset{I}{I}$ & $\begin{array}{l}2360 \\
2772 \\
513^{2}\end{array}$ & $\begin{array}{l}\text { I } 2 \\
\text { I I } \\
23\end{array}$ & $\begin{array}{l}0.51 \\
0.40 \\
0.45\end{array}$ & $\begin{array}{l}\text { I } \\
2 \\
3\end{array}$ \\
\hline $4 \times 600$ & 2 & $\underset{I+I I}{I I}$ & $\begin{array}{l}2252 \\
2540 \\
479^{2}\end{array}$ & $\begin{array}{l}\text { I3 } \\
\text { IO } \\
23\end{array}$ & $\begin{array}{l}0.5^{8} \\
0.39 \\
0.48\end{array}$ & $\begin{array}{l}0 \\
I \\
I\end{array}$ \\
\hline $4 \times 600$ & 4 & $\underset{I+I I}{I}$ & $\begin{array}{l}2067 \\
2339 \\
4406\end{array}$ & $\begin{array}{l}\text { I } 7 \\
\text { I } 4 \\
3 \text { I }\end{array}$ & $\begin{array}{l}0.82 \\
0.60 \\
0.70\end{array}$ & $\begin{array}{l}I \\
I \\
2\end{array}$ \\
\hline $8 \times 300$ & 1 & $\underset{I}{I}$ & $\begin{array}{l}2189 \\
2388 \\
4577\end{array}$ & $\begin{array}{r}12 \\
5 \\
17\end{array}$ & $\begin{array}{l}0.55 \\
0.21 \\
0.37\end{array}$ & $\begin{array}{l}3 \\
0 \\
3\end{array}$ \\
\hline
\end{tabular}

* Repeats (occurrence of same mutation on successive leaves of tiller) are scored as one mutational event.

treatments were carried out in November ; in the intervals between fractions and at all times after irradiation plants were kept in a heated greenhouse. Scoring of the material for leaf numbers and mutations commenced after ten weeks, and after that time at fortnightly intervals for another ten weeks. The total number of leaves and mutations over all scoring dates are given in table 3 , and text-figs. 3 and 4 . There was. no differential effect of fractionation on leaf production-but a very considerable effect on induction of mutations. The two clones will 


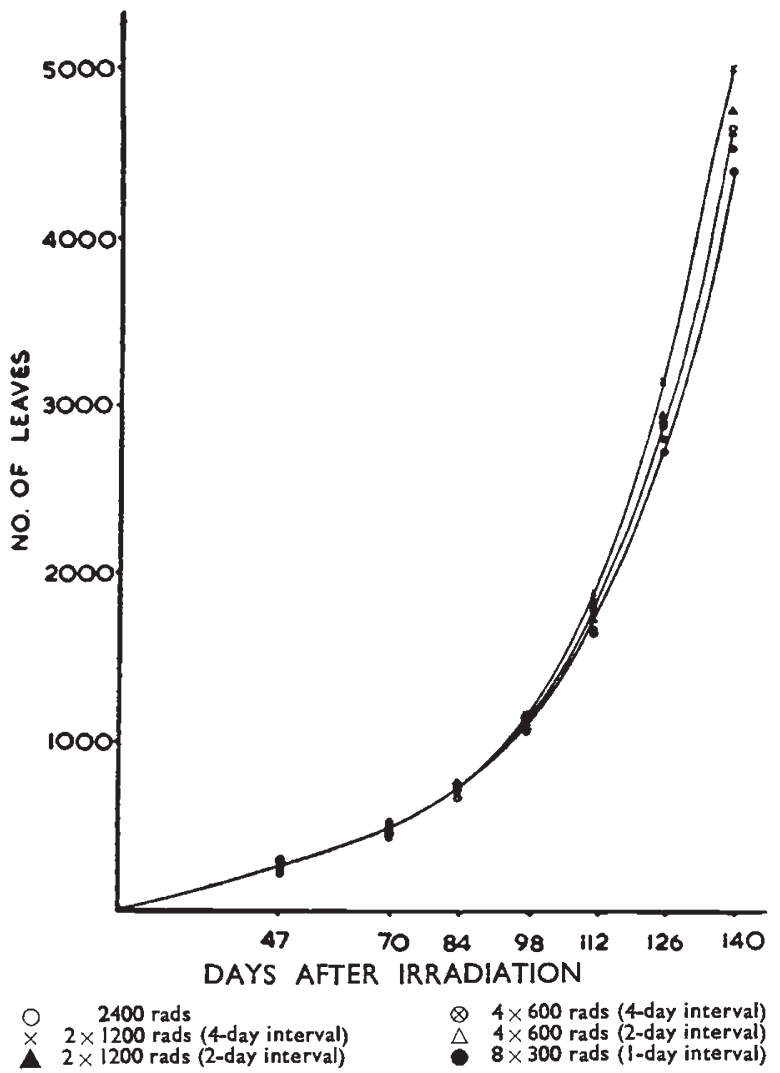

TEXT-Fig. 3.-Effect of dose fractionation on leaf production (T. repens).

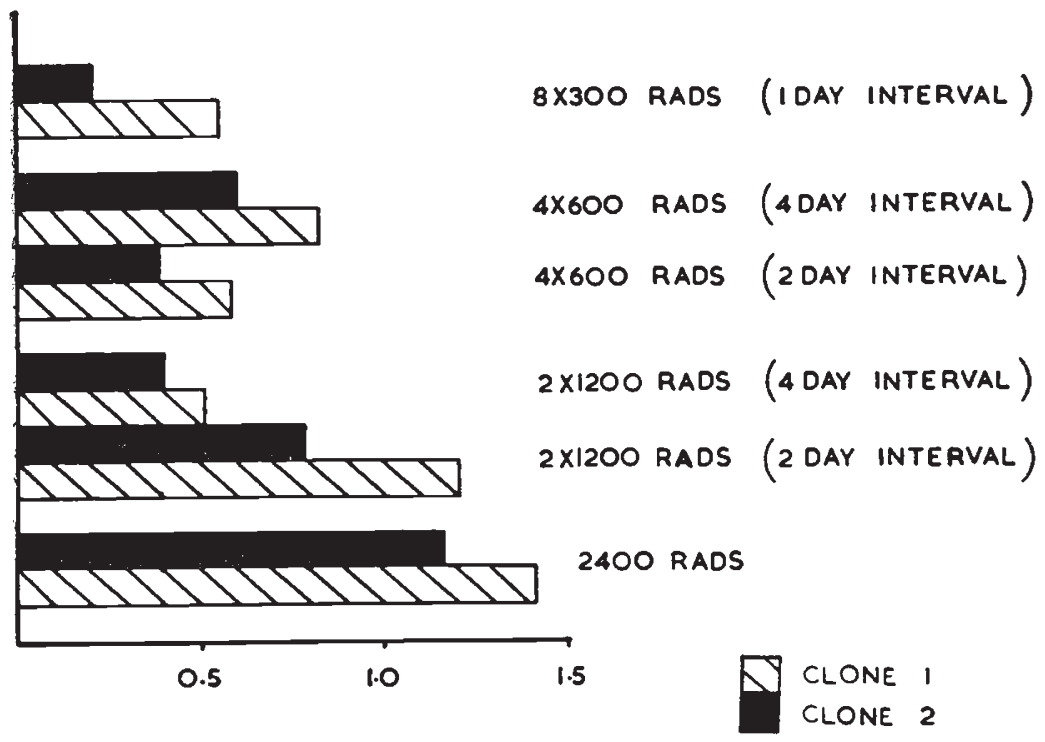

$\%$ MUTATIONS

TEXT-FIG. 4.-Effect of dose fractionation and differing time intervals between fractions on induction of somatic mutations by $\gamma$ radiation (V locus in $\tau$. repens; irradiated in November). 
be considered together initially and mean values for both genotypes utilised in the comparisons of the effects of fractionation. 2400 rads given in one acute treatment produced a mean frequency of $\mathrm{I} \cdot 28$ per cent. mutations; if the total dose was given in two fractions of 1200 rads separated by a two-day interval, there was a slight, but not significant, decrease to $0 \cdot 98$ per cent. (table 4 ). Separating the fractions

TABLE 4

$\chi^{2}$ and probability values for differences in mutation frequencies

\begin{tabular}{|c|c|c|c|}
\hline Comparison ( $\chi^{2}$ test) & Clone & $x^{2}$ & Probability \\
\hline (a) Clone I $v$. Clone II & & $6 \cdot 230$ & $0.02-0.01$ \\
\hline (b) All treatments & $\underset{I+I I}{I}$ & $\begin{array}{l}19 \cdot 232 \\
25 \cdot 249 \\
44^{\circ} \cdot 4^{8}\end{array}$ & $\begin{aligned} 0.01 & -0.001 \\
& <0.001 \\
& <0.001\end{aligned}$ \\
\hline (c) 2400 v. $2 \times$ I 200 (2-day interval) & $\underset{\substack{I \\
I+I I}}{I}$ & $\begin{array}{l}0 \cdot 436 \\
1 \cdot 897 \\
2 \cdot 333\end{array}$ & $\begin{array}{l}0.7-0.5 \\
0.2-0.1 \\
0.5-0.3\end{array}$ \\
\hline (d) $2400 v \cdot 4 \times 600$ (4-day interval) & $\underset{I+I I}{I}$ & $\begin{array}{l}3 \cdot 314 \\
4 \cdot 417 \\
7 \cdot 731\end{array}$ & $\begin{array}{r}0.1-0.05 \\
0.05-0.02 \\
0.05-0.02\end{array}$ \\
\hline (e) $2 \times 1200$ ( 2 day) $1.2 \times 1200$ (4 day) & $\underset{I}{I}$ & $\begin{array}{l}6 \cdot 523 \\
3 \cdot 210 \\
9 \cdot 733\end{array}$ & $\begin{array}{l}0.02-0.01 \\
0.10-0.05 \\
0.01-0.001\end{array}$ \\
\hline (f) $4 \times 600$ ( 2 day) $v \cdot 4 \times 600$ ( 4 day) & $\underset{I+I I}{I}$ & $\begin{array}{l}0.949 \\
\text { I.065 } \\
2 \cdot 014\end{array}$ & $\begin{array}{l}0.5-0.3 \\
0.5-0.3 \\
0.5-0.3\end{array}$ \\
\hline (g) $2 \times 1200$ ( 2 day) $0.4 \times 600$ ( 2 day $)$ & $\stackrel{\text { I }}{I I}$ & $\begin{array}{l}4^{-8} 83_{1} \\
3^{\circ} .036 \\
7 \cdot 867\end{array}$ & $\begin{array}{l}0.05-0.02 \\
0.10-0.05 \\
0.02-0.01\end{array}$ \\
\hline (h) $2 \times 1200$ ( 4 day) $v .4 \times 600$ (4 day) & $\stackrel{\text { I }}{I I}$ & $\begin{array}{l}\mathrm{I} \cdot 692 \\
\mathrm{r} \cdot 045 \\
2 \cdot 737\end{array}$ & $\begin{array}{l}0.2-0.1 \\
0.5-0.3 \\
0.3-0.2\end{array}$ \\
\hline (i) $4 \times 600$ ( 4 day) $v .8 \times 300$ (I day) & $\underset{I}{I}$ & $\begin{array}{l}I \cdot 170 \\
4 \cdot 498 \\
5 \cdot 668\end{array}$ & $\begin{array}{c}0.3-0.2 \\
0.05-0.02 \\
0.10-0.05\end{array}$ \\
\hline (j) $2 \times 1200(2$ day) $v \cdot 4 \times 600(4$ day $)$ & $\underset{I}{I}$ & $\begin{array}{l}\text { I } 468 \\
0 \cdot 496 \\
\text { I. } 964\end{array}$ & $\begin{array}{l}0.3-0.2 \\
0.5-0.3 \\
0.5-0.3\end{array}$ \\
\hline
\end{tabular}

by an interval of four days resulted in a very significant decrease to 0.45 per cent. mutations. If some of the mutations were two-hit events, then it may be assumed that over two days, damaged sites produced by the first could interact with those produced by the second. fraction, but if there was a four-day interval such an interaction could not occur. The small quadratic component in the dose-response function indicates that this non-interaction could not be the sole reason for the difference between the two- and four-day intervals, and no adequate explanation is available. 
The $4 \times 6$ oo rads treatments, separated either by two- or four-day intervals gave different results. Both long and short intervals resulted in a similar yield of mutations. This indicates an effect of dose on a repair mechanism. After I 200 rads repair was delayed and interaction could occur over two days, whereas after 6oo rads repair could occur in less than two days. An analogy can be made with the results of Wolff and Atwood (1954) who found that the delay in rejoining of chromosome breaks was dose dependent.

The $8 \times 300$ rads treatment, separated by one-day intervals, gave the lowest mean frequency of mutations of all, 0.37 per cent. The consistent reduction in the rate after fractionation could be attributed to several factors, including :-

(I) The two-hit nature of some of the events, and non-interaction between successive fractions ; but as explained previously, this factor is not likely to be of great importance.

(2) A retarding of cell division after the first fraction so that later fractions act on a population comprising more of resting, and hence of more resistant, cells. Again it is doubtful whether the variation in the sensitivity of cells at different stages of development can account entirely for the reduction observed on fractionation.

(3) The physiological effect of the first fraction of radiation may affect the sensitivity of cells to a later fraction (Lane, I952).

The amount of physiological damage and induced lethality, as measured in terms of leaf production, was not influenced differentially by any of the fractionation treatments. It may be assumed from the previous experiment that a dose of 2400 rads results in a reduction of leaf production. Since the effect on leaf growth is probably multi-hit a reduction of damage might have been expected after fractionation, but the absence of any such reduction indicates that in direct contrast to the response of mutational events, a complete interaction of the effects of separate fractions was possible.

\section{COMPARISON OF ACUTE, FRACTIONATED AND CHRONIC DOSES}

In order to elucidate further the nature of the dose-fractionation phenomenon, and to obtain quantitative information on the comparative efficiencies of the different treatments, a further experiment was undertaken. Details of the treatments are given in table 5. Each treatment sample consisted of four similar tillers of clone I (see previous experiment). These were defoliated prior to treatment and exposed at room temperature at a dose rate of 1 I 22 rads per hour, apart from the chronic irradiation, for which treatment the rate was 25 rads per hour. The plants were irradiated in May and maintained in a greenhouse between and after all treatments.

Numbers of leaves and mutations were first scored after five weeks and afterwards at three-weekly intervals for a further six weeks-total values for all scoring dates are given in table 5 and text-fig. 5 . 
The acute treatments, 2400 rads and 1200 rads were replicatedone on the first day and the other on the fifth day of the experiment, to check on any possible differences due to time of treatment. No

TABLE 5

Numbers of normal and mutant leaves after acute, fractionated and chronic doses

\begin{tabular}{|c|c|c|c|c|}
\hline \multirow{2}{*}{ Dose in rads } & \multirow{2}{*}{ Day irradiated } & \multirow{2}{*}{ Total no. leaves } & \multicolumn{2}{|c|}{ Leaves with mutations } \\
\hline & & & Number & Percentage \\
\hline 2400 & I & $3^{67} \mathrm{I}$ & 122 & $3 \cdot 3^{2}$ \\
\hline 2400 & 5 & $3^{254}$ & I I 6 & $3 \cdot 57$ \\
\hline $2 \times 1200$ & I and 5 & 3247 & 71 & $2 \cdot 19$ \\
\hline $2 \times 1200$ & 3 and 5 & 3187 & 77 & $2 \cdot 4^{2}$ \\
\hline 2400 chronic & I to 5 & 3575 & 33 & $0 \cdot 92$ \\
\hline 1200 & I & 3 I 29 & $5^{6}$ & $\mathbf{r} \cdot 79$ \\
\hline I 200 & 5 & $35^{8 I}$ & $5^{I}$ & $I \cdot 42$ \\
\hline $2 \times 600$ & I and 5 & 3 I 59 & 33 & $r \cdot 05$ \\
\hline $2 \times 600$ & 3 and 5 & 3602 & 42 & $\mathrm{I} \cdot \mathrm{I} 7$ \\
\hline 600 & I & 3402 & $3^{2}$ & 0.94 \\
\hline
\end{tabular}

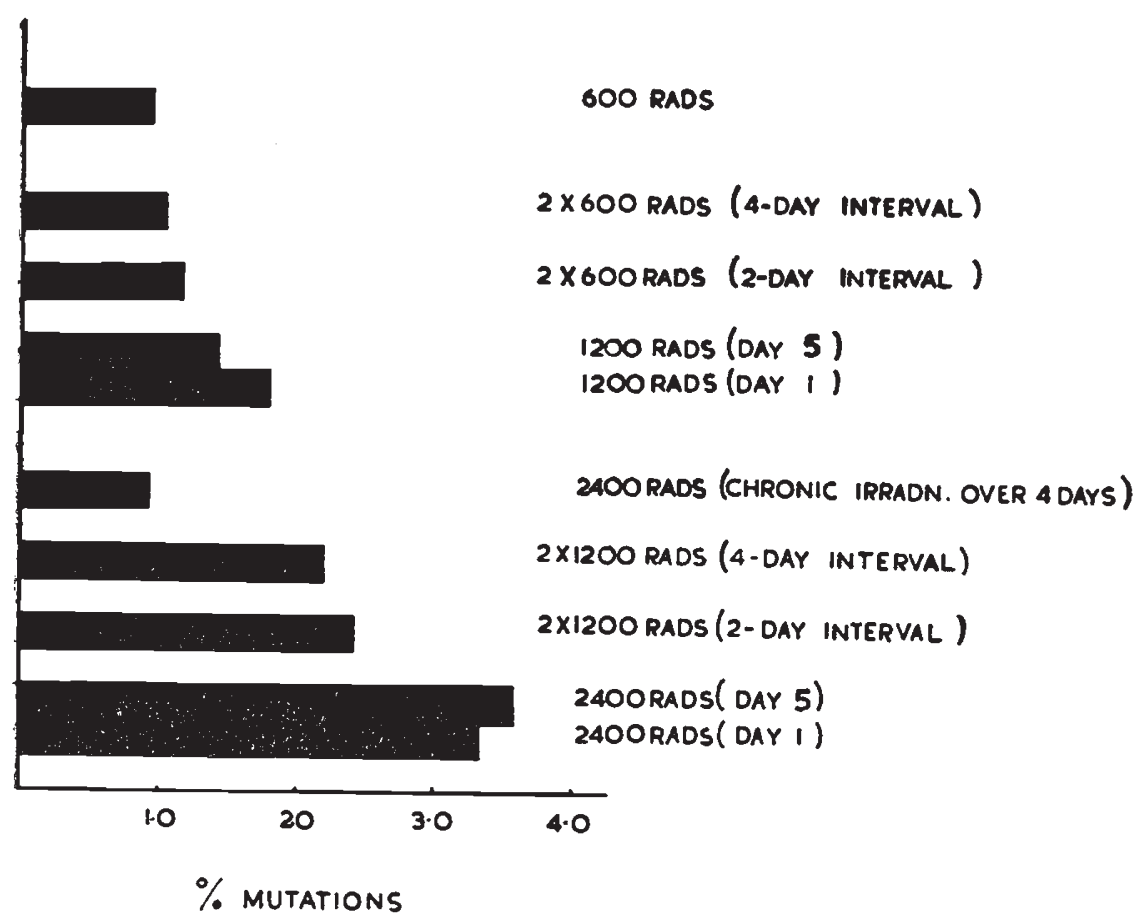

TEXT-FIG. 5.-Effects of acute, fractionated and chronic doses of $\gamma$ radiation on the induction of somatic mutations (V locus in T. repens; irradiated in May).

significant differences were found due to time of treatment (table 6). Splitting the dose into two fractions of 1200 rads reduced the effect very considerably, but the time intervals of two or four days between fractions had no differential effect. This is in marked contrast to the 
previous experiments and a possible explanation may lie in the different seasons at which the materials were treated and grown. Plants in this experiment were irradiated in May, those in the previous one in November. At the former time conditions of growth were at an optimum-damage induced by the first fraction could be repaired more quickly than in November and hence there would be less interaction between the two fractions. The two $\times 6$ oo rads fractionation treatments were also similar, whether separated by two or four days. There was a 33 per cent. reduction in the number of mutations recovered when the 2400 rads dose was fractioned into two doses of I 200 rads and. a $3^{I}$ per cent. reduction from I 200 rads to two doses of 600 rads. The values obtained for two fractions of I 200 rads do not equal or

TABLE 6

$\chi^{2}$ and probability values for differences in mutation frequencies

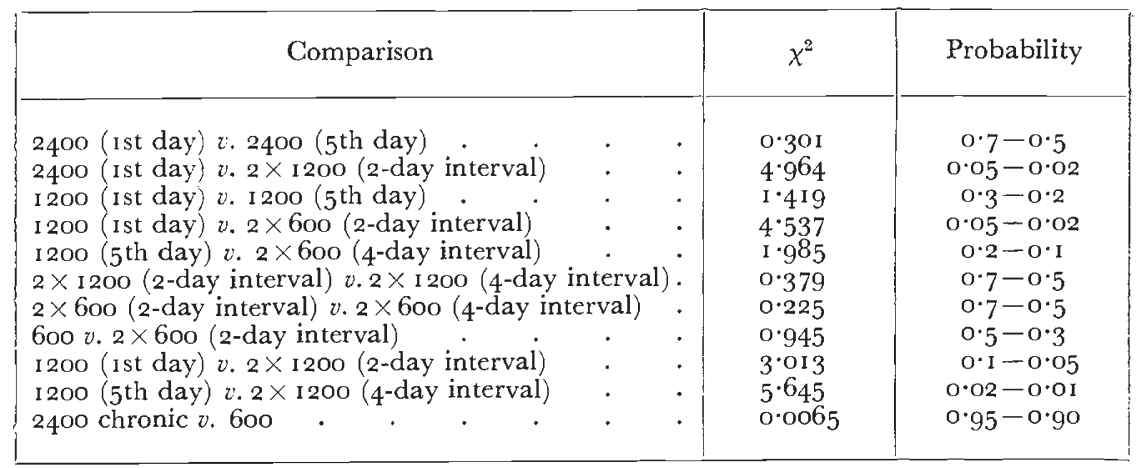

even approach twice the value obtained with one treatment of 1200 rads. Similarly there was no significant difference between one dose of 600 rads and two doses of 600 rads separated by either two or four days. When 2400 rads were given as a chronic dose, at a rate of 25 rads per hour, the numbers of mutations recovered were not significantly different from that obtained with a single acute dose of 6oo rads.

As in the previous experiment the explanation for the reduction in recoverable mutations after fractionation of the dose, or chronic exposure, may be found in a changed sensitivity of cells after the initial treatment. Irrespective of whether the events being scored are one-hit, or multi-hit, which can or cannot interact, the total number of mutations from two fractions should still equal twice the value obtained from one fraction alone, but this doubled value was not obtained.

\section{EFFECT OF GENOTYPE ON MUTABILITY}

Pronounced and consistent differences were noted in the radiosensitivity, as measured in terms of induced mutations at the Vby locus, of the two genotypes used in the first fractionation experiment (table 3 and fig. 4). The two clones used were propagated vegetatively from sister plants-the progeny of two common parents. Clone I 
consistently produced more mutations than Glone II, $\chi_{(1)}^{2}=6 \cdot 23, \mathrm{P}$ $=0.02$ to 0.01 (table 4$)$. Such a pronounced difference in the sensitivity of one locus in plants of quite similar genetic background has not previously been reported.

\section{MUTANT PHENOTYPES}

The mutant phenotypes produced on irradiating tissue heterozygous for Vby and the recessive "no-mark" allele could be separated into two classes. The first included those in which either both or only one of the component parts of the mark had been lost (plate I, fig. 2) and the second, those exhibiting a modified form of mark (plate I, figs. 3 and 4 ). All mutations appeared completely viable, and whole tillers of mutant phenotypes were propagated.

In the first class, by far the most frequent, the loss of the whole mark simulated the double recessive $v v$ phenotype and the loss of the yellow tip the $\mathrm{V}^{\mathrm{B}}$ phenotype (Brewbaker, 1955). Artificial and natural $V^{B}$ phenotypes were indistinguishable morphologically. Loss of the white $\mathrm{V}$ resulted in a phenotype which, as far as is known, does not occur naturally. Two such yellow-tip phenotypes were found (plate I, fig. 2) differing in intensity of the yellow coloration, and in the area of the yellow tip. The relative frequencies with which the loss phenotypes occurred as whole leaf mutations, summed over the three experiments, were :-

\section{Loss of whole mark 103 \\ Loss of white $\mathrm{V} \quad 80$ \\ Loss of yellow tip 18}

The implications of the relative frequencies of occurrence and nature of these mutant phenotypes, in relation to the structure and possible complexity of the $V$ by locus has already been discussed (Davies and Wall, I959). The second class of mutants included some in which the white $\mathrm{V}$ had been reduced to spots and the yellow tip reduced in size (plate I, fig. 3) and others in which the whole mark had been reduced in intensity (plate I, fig. 4). Again these phenotypes are not known to occur naturally. Genetical analyses of the mutant phenotypes has not been possible as the mutants proved to be chimæric and the flowers derived from normal tissue.

\section{DISCUSSION}

It must be emphasised that a given radiation treatment in one of the experiments reported need not necessarily have the same percentage mutations recorded as the same treatment in another experiment. The reason for this is that from the time of appearance of the first mutation, there is a definite increase in the frequency up to a given time, after which the frequency decreases, while the number of leaves increases exponentially all the time. The total percentage mutations scored will depend on the stage in this cycle at which scoring is terminated. 
Plate II

120 curie $\mathrm{Co}^{60}$ installation at the Wantage Radiation Laboratory. 


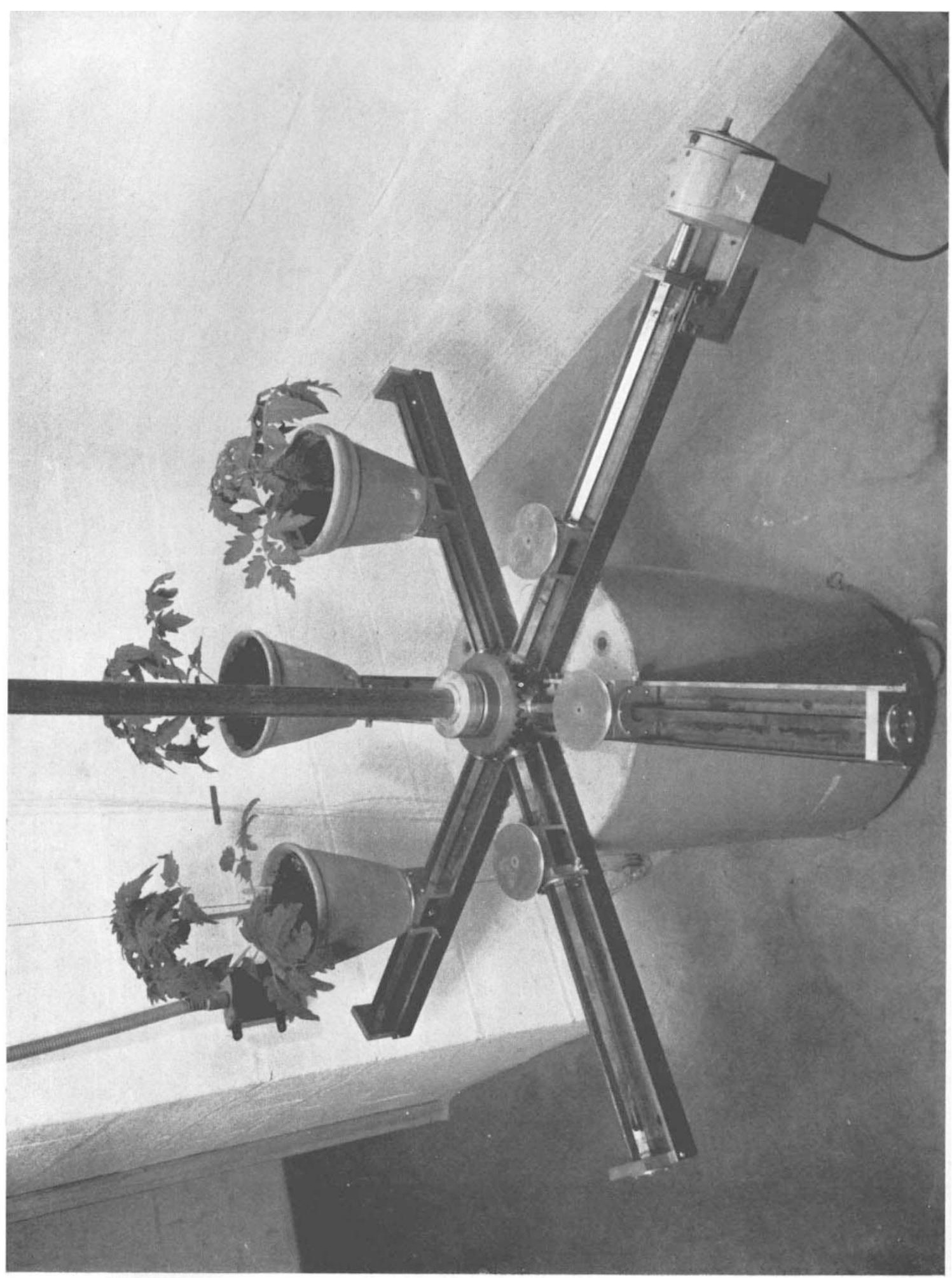


Again the rate of development of the cycle is directly dependent on the environment. As scoring did not terminate at the same stage in all three experiments and as they were undertaken at different seasons a comparison of the percentage mutant leaves between experiments is not valid, but within any given experiment comparisons are accurate.

The response of this tissue to gamma radiation, in terms of induced mutations at the Vby locus has been shown to be dependent on a number of factors. The relation of frequency to dose fitted both a linear and quadratic function; the first part of the frequency dose response (up to 1500 rads) appeared to fit a quadratic more closely than a linear function. At higher doses this trend was not maintained, and the apparent overall agreement with linearity could have been due to an elimination, through dominant lethal aberrations, of the most badly damaged cells at the highest doses. Thus multi-hit events may have constituted a proportion of the events scored, and these would to some extent account for the reduction in the frequency of mutations recovered when a given dose was fractionated, or the dose rate was lowered. This cannot be the sole explanation for the reduction observed, as the value obtained after exposure to two equal fractions separated by two or four days usually did not approach twice that obtained with a dose equivalent to one fraction. Again the extent of the reduction due to a lowering of the dose rate was shown by the fact that 2400 rads given at a rate of 25 rads per hour produced a number of mutations similar to 600 rads given at a rate of I 100 rads per hour. It is known that ionising radiations affect cell development, inhibiting D.N.A. synthesis and retarding the development of the mitotic cycle, but even if the first fraction retarded or even inhibited division prior to and during exposure to the second fraction, it is unlikely that the variations in the sensitivity of different stages of dividing and resting cells could account entirely for the reduction observed on fractionating a given dose. Again Lane (I952) has suggested that one fraction may modify the sensitivity of a tissue to a later fraction but others have failed to confirm this result. A fuller elucidation of the fractionation effect must await further investigation.

The results of Russell et al. (I958, I 959) are of interest in connection with the effect of intensity on mutation rate. They have shown that the mutation rates of oocytes and spermatogonia, but not of spermatozoa, are dependent on dose rate, and have suggested that the differential response of these classes is related to the possibility of a repair of damaged sites at low dose rates in oocytes and spermatogonia but not in spermatozoa.

A genetic control of mutational response at a given locus has been clearly shown in the present experiments. Though the two clones utilised were derived from two full sib plants, as Trifolium repens is an obligate outbreeder the genetic constitution of the sibs could have differed to a marked extent. Several hypotheses can be proposed $o$ account for the difference, but all lack experimental verification. 
Differences could exist in the nature and amounts of protective or sensitising substances, in the respiration rates and oxygen contents, and in the metabolic rates of the tissues. Genetic control of spontaneous chromosome breakage is known to occur and in this instance a similar control of frequency or localisation of induced breaks or mutations could occur.

From a plant breeder's viewpoint these studies have many implications. The occasional desirability of separating two loci so closely linked that crossing-over either occurs extremely infrequently or not at all, has been emphasised (Frankel, 1958) and in the present experiment this was achieved. The new phenotypes produced may prove valuable in contributing to a solution of the difficulties of seed certification in clovers, where the problem of authenticity is complicated (Davies, 1957). A programme is now being undertaken in which seeds heterozygous for $\mathrm{V}^{\text {by }}$ and $v$ are being irradiated in an attempt to produce mutants similar to those illustrated in plate I, figs. 2, 3 and 4 and which will not be chimæric. Again the information obtained from the comparisons of acute, chronic and fractionated doses has provided more critical data for determining the possible value of gamma fields as a tool for the plant breeder. In terms of the frequency of induction of mutations it is obvious that acute are more efficient than chronic treatments, and though it has been claimed that gamma fields are advantageous for treating large specimens such as fruit trees, it has yet to be demonstrated that the treatment of scions or cuttings with acute doses is in any way less efficient than the treatment of whole trees with chronic doses.

\section{SUMMARY}

I. Two clonal lines of Trifolium repens heterozygous for the leaf marking alleles $V^{\text {by }}$ and $v$ have been utilised in a study of induced somatic mutations at the Vby locus.

2. Data are given on the dose-response relationship, and on the comparative efficiencies of acute, fractionated and chronic doses of gamma radiation.

3. Fractionated and chronic doses have in all instances given considerably lower frequencies of mutations than acute doses. This can in part be attributed to the multi-hit nature of some of the events scored, to an increase in the proportion of resting and hence more resistant cells in tissues exposed to an initial fraction of radiation, and to a changed sensitivity of irradiated cells.

4. A pronounced effect of genotype on the mutagenic sensitivity of the $V^{\text {by }}$ locus was demonstrated.

5. Two elements have been separated at the Vby locus, which as far as is known are not separable by crossing-over, and mutant phenotypes produced which do not occur naturally.

Acknowledgment.-.-We are grateful to Professor K. Mather for his helpful comments and criticism of the script. 


\section{REFERENCES}

BREivaAker, J. L. I955. V-leaf markings of white clover. 7. Hered., 46, i I $5^{\text {- }} 23$. BREWBAKER, J. L., AND CARNAHAN, H. L. I956. Leaf marking alleles in white clover. F. Hered., 47, I03-104.

CUANY, R. L., SPARROW, A. H., AND POND, v. I958. Genetic response of $A$. majus to acute and chronic plant irradiation. Z.I.A.V., 89, 7-I3.

DAVIES, D. R., AND WALL, E. T. 1959. Separation by gamma irradiation of two elements at the $\mathrm{V}^{\text {by }}$ locus in Trifolium repens. Nature, I84, I957-1958.

DAvies, W. E. 1957. Breeding better clovers. Agr. Rev., 3, I 2-18.

fRANkel, o. H. 1958. The dynamics of plant breeding. 7. Aust. Inst. Agric. Sci., 24, II 2-I I 3 .

KAPLAN, R. W. 1951. Chromosomen und Faktormutationsraten in Gerstenkornern bei verschiedenartigen Quellungsbehandlungen oder Kalte wahrend oder nach der Rontgenbestrahlung sowie bei Dosisfraktionierung. Z.I.A.V., 83, 347-382.

LANE, G. R. 1952. Interpretation in X-ray chromosome breakage experiments. Heredity, 6, Suppl., 23-34.

MUller, H. J. 1954. In Radiation Biology, vol i, 475-626. Ed. Hollaender. McGrawHill.

RUSSELL, W. L., RUSSELl, L. B., AND KELLy, E. M. 1958. Radiation dose-rate and mutation frequency. Science, 128 , I546-I 550 .

RUSSEll, W. L., RUSSELL, L. B., AND CUPP, M. B. I959. Dependence of mutation frequency on radiation dose rate in female mice. Proc. Nat. Acad. Sci., 45, I 8-23.

SAX, K., KING, E. D., AND LUIPPold, H. 1955. The effects of fractionated X-ray dosage on the frequency of chromatid and chromosome aberrations. Rad. Res., 2, I 7 I-I 79 .

SCHOOLER, A. B., NILAN, R. A., AND PHillips, L. L. I957. The effects of fractionated doses of X-rays on dormant barley seeds. Northwest Science, 3I, 80-9I.

STEFFENSEN, D., AND ARNASON, T. J. I954. Frequency of chromosome aberrations produced by fractional doses of X-rays in Tradescantia. Genetics, 39, 220-228.

WOLFF, S., AND ATWOOD, K. C. 1954. Independent X-ray effects on chromosome breakage and reunion. Proc. Nat. Acad. Sci. U.S., 40, г87-192. 